\title{
Hof van Justitie oordeelt over mandaat van ECB inzake monetair beleid
}

\author{
Onafhankelijkheid van de ECB gewaarborgd?
}

\author{
M.L. Louisse
}

\section{Inleiding}

In maart 2015 is de Europese Centrale Bank (ECB) begonnen met een programma van kwantitatieve verruiming $(\mathrm{QE})$. Onder dit programma koopt de $\mathrm{ECB}$, al dan niet via de nationale centrale banken van de eurolidstaten, staatsobligaties en obligaties uitgegeven door Europese instellingen op van de bankensector in het eurogebied. Het instrument van kwantitatieve verruiming is een instrument van monetair beleid dat nog niet eerder is ingezet door de ECB. Over dit instrument zijn dan ook de nodige vragen gesteld in de media en de politiek, (Kamerstukken II 2014/15, 21501-07, 1221, 1222, 1226, 1228 en 1229) ${ }^{1}$ met name gelet op het feit dat de ECB voor de aankoop van de obligaties nieuw centralebankgeld uitgeeft en daarmee de geldhoeveelheid in de eurozone vergroot. ${ }^{2}$ De vraag is of dit wel past binnen het mandaat dat de ECB heeft inzake monetair beleid en in hoeverre deze vraag kan/mag worden beantwoord, nu de ECB haar mandaat in onafhankelijkheid uitvoert. ${ }^{3}$

1 Een aantal Tweede Kamerleden heeft moties ingediend over het QE-programma. Tweede Kamerleden Van Dijck, Omtzigt en Schouten vonden het opkoopprogramma van de ECB 'onwenselijk'. Omtzigt en Schouten vroegen zich af of het opkoopprogramma van de ECB in overeenstemming is met de Europese verdragen. Tweede Kamerlid Harbers sprak uit dat een besluit tot kwantitatieve verruiming niet mag leiden tot vergrote risicoverevening en herverdeling van de financiële risico's tussen eurolidstaten. Tweede Kamerlid Merkies sprak uit dat het opkoopprogramma zo moet worden vormgegeven dat het ten gunste komt van de reële economie en niet leidt tot nieuwe bubbels op de financiële markten.

2 Op grond van art. 128 lid 1 VWEU en art. 16 van het Protocol (nr. 4) betreffende de statuten van het Europees Stelsel van centrale banken en van de Europese Centrale Bank (hierna: het Protocol) heeft de Raad van Bestuur van de ECB het alleenrecht machtiging te geven tot uitgifte van eurobankbiljetten. Op grond van deze bepalingen kunnen de ECB en nationale centrale banken van de eurolidstaten eurobankbiljetten uitgeven. Er zijn geen kwantitatieve of andere beperkingen opgelegd, omdat het in omloop brengen van bankbiljetten een door vraag gestuurd proces is. Zie overwegingen 1 en 3 en art. 2 van het Besluit van de Europese Centrale Bank van 13 december 2010 betreffende de uitgifte van eurobankbiljetten (herschikking) (ECB/2010/29).

3 Naar aanleiding van de moties van de Tweede Kamerleden over het QE-programma (zie noot 1) heeft de minister van Financiën op 9 februari 2015 een brief gestuurd aan de voorzitter van de Tweede Kamer, waarin hij - mijns inziens terecht - opmerkt dat het niet aan het kabinet is om zich uit te spreken over de wijze waarop de ECB in onafhankelijkheid haar mandaat uitvoert (Kamerstukken II 2014/15, 21501-07, 1235). 
Op 16 juni 2015 heeft het Hof van Justitie van de Europese Unie (hierna: Hof van Justitie) zich uitgelaten over het mandaat van de ECB naar aanleiding van prejudiciële vragen van het Bundesverfassungsgericht (het Duitse grondwettelijk hof) over de verenigbaarheid met het Europese recht, en meer in het bijzonder met het mandaat van de ECB, van een met het QE-programma vergelijkbaar ander instrument van monetair beleid: het Outright Monetary Transactions-programma (OMT-programma). ${ }^{4}$

In dit artikel behandel ik het arrest van het Hof van Justitie, de mogelijke aanknopingspunten die dit arrest biedt voor de beantwoording van de vraag of de ECB met het QE-programma binnen haar mandaat blijft, en de mogelijke gevolgen die dit arrest heeft voor de onafhankelijkheid van de ECB. Voor een goed begrip van de (technische) materie zal ik allereerst een achtergrond schetsen van de functies en inrichting van de ECB en de instrumenten van het monetair beleid die de ECB kan inzetten.

\section{De functies en inrichting van de ECB}

Met de verwezenlijking van de Europese Economische en Monetaire Unie (EMU) in 1999 was er behoefte aan een nieuwe supranationale monetaire organisatie, de $\mathrm{ECB}$, en de integratie van de nationale centrale banken van de lidstaten van de Europese Unie (hierna: lidstaten) in een Europees Stelsel van Centrale Banken (ESCB). De ECB en het ESCB werden op 1 juni 1998 bij het Verdrag tot oprichting van de Europese Gemeenschap (EG-Verdrag) ${ }^{5}$ opgericht. $^{6}$ Het ESCB en de ECB voeren hun taken en werkzaamheden uit overeenkomstig de bepalingen van het EG-Verdrag (tegenwoordig het Verdrag betreffende de werking van de Europese Unie, VWEU) en het Protocol (nr. 4) betreffende de statuten van het Europees Stelsel van centrale banken en van de Europese Centrale Bank (het Protocol). ${ }^{7}$

\subsection{Functies}

De ECB heeft tot taak erop toe te zien dat de aan het Eurosysteem ${ }^{8}$ opgedragen taken worden uitgevoerd, hetzij door de ECB, hetzij via de nationale centrale banken van de eurolidstaten. ${ }^{9}$ De belangrijkste taken van het Eurosysteem ${ }^{10}$ zijn het bepalen en ten uitvoer leggen van het monetair beleid van het eurogebied, het

4 HvJ EU 16 juni 2015, C-62/14, ECLI:EU:C:2015:400 (Gauweiler). Zie voor de specificaties van het OMT-programma ECB, Technical features of Outright Monetary Transactions, 6 februari 2012.

$5 \quad$ PbEU 1997, C 340/173.

6 Art. 8 van het EG-Verdrag.

7 PbEU 2012, C 326/230.

8 Zolang niet alle lidstaten de euro als munt hebben, bestaat ook het Eurosysteem. Dit wordt gevormd door de ECB tezamen met de presidenten van de nationale centrale banken van de eurolidstaten. Gelet op art. 43 van het Protocol zijn de meeste bepalingen van het Protocol van toepassing op het Eurosysteem in plaats van op het ESCB.

9 Art. 9.2 van het Protocol.

10 Hoewel de tekst van art. 3.1 van het Protocol verwijst naar het ESCB, dient in plaats daarvan het Eurosysteem te worden gelezen, gelet op art. 43 van het Protocol. 
verrichten van valutamarktoperaties, het aanhouden en beheren van de externe reserves van het eurogebied (portefeuillebeheer) en het bevorderen van een goede werking van het betalingsverkeer. ${ }^{11}$ Andere daarmee samenhangende taken zijn de uitgifte van eurobankbiljetten ${ }^{12}$ en het verzamelen van de benodigde statistische gegevens voor de taken van het Eurosysteem. ${ }^{13}$

Het handhaven van prijsstabiliteit is het hoofddoel van het Eurosysteem en de kern van het monetair beleid van de ECB voor het eurogebied. ${ }^{14}$ Prijsstabiliteit houdt in dat zowel langdurige inflatie als deflatie moet worden vermeden. ${ }^{15}$ De doelstelling van de ECB is een inflatie van onder, maar dicht bij de $2 \%$. Als gevolg van de crisis wordt dit percentage al geruime tijd niet benaderd. In juni 2015 bedroeg de inflatie in het eurogebied $0,2 \% .{ }^{16}$ Om prijsstabiliteit te bewerkstelligen heeft het Eurosysteem een aantal monetaire beleidsinstrumenten tot zijn beschikking. Hier ga ik in paragraaf 3 nader op in.

Naast haar monetairbeleidsfunctie heeft de ECB sinds 4 november 2014 ook een toezichtsfunctie. ${ }^{17}$ Op 4 november 2014 is het gemeenschappelijk toezichtsmechanisme (Single Supervisory Mechanism, SSM) ${ }^{18}$ van start gegaan. Het SSM houdt, kort gezegd, in dat de ECB bedrijfseconomisch (prudentieel) toezicht houdt op significante banken in de eurolidstaten (en in niet-eurolidstaten indien de ECB een nauwe samenwerking is aangegaan met de bevoegde autoriteit van de betreffende niet-eurolidstaat ${ }^{19}$ ) en de nationale centrale banken op de niet-significante banken in de eurolidstaten. ${ }^{20}$ Het SSM maakt onderdeel uit van de Bankenunie. De Bankenunie omvat naast het SSM een gemeenschappelijk afwikkelingsmechanisme (Single Resolution Mechanism, SRM) ${ }^{21}$ voor banken die onder het

11 Art. 3 van het Protocol.

12 Zie noot 2.

13 Art. 128 VWEU; art. 16 en 5 van het Protocol.

14 Art. 127 lid 1 VWEU; art. 2 van het Protocol.

15 ECB, Prijsstabiliteit; waarom is dat belangrijk voor jou?, april 2009, p. 24.

16 Eurostat, Annual inflation down to $0.2 \%$ in the euro area, Newsrelease euroindicators, 129/2015, 16 juli 2015.

17 De basis hiervoor is gelegen in art. 127 lid 6 VWEU. Op grond van dit artikel kunnen aan de ECB specifieke taken worden opgedragen betreffende het beleid op het gebied van het bedrijfseconomisch toezicht op kredietinstellingen en andere financiële instellingen, met uitzondering van verzekeringsondernemingen.

18 Verordening (EU) 1024/2013 van de Raad van 15 oktober 2013 waarbij aan de Europese Centrale Bank specifieke taken worden opgedragen betreffende het beleid inzake het prudentieel toezicht op kredietinstellingen (hierna: SSM-Verordening).

19 Art. 7 van de SSM-Verordening.

20 Art. 6 van de SSM-Verordening. Om het (nog) gecompliceerder maken is de ECB voor bepaalde toezichtstaken (waaronder de vergunningverlening) ook verantwoordelijk ten opzichte van nietsignificante banken in het eurogebied.

21 Verordening (EU) 806/2014 van het Europees Parlement en de Raad van 15 juli 2014 tot vaststelling van eenvormige regels en een eenvormige procedure voor de afwikkeling van kredietinstellingen en bepaalde beleggingsondernemingen in het kader van een gemeenschappelijk afwikkelingsmechanisme en een gemeenschappelijk afwikkelingsfonds en tot wijziging van Verordening (EU) 1093/2010. 
SSM vallen en een single rulebook met geharmoniseerde regels voor de banken in alle lidstaten. ${ }^{22}$

\subsection{Inrichting}

De ECB heeft als besluitvormende organen een Raad van Bestuur, een directie en een Algemene Raad. ${ }^{23}$ De Raad van Bestuur formuleert het monetair beleid en de directie voert het monetair beleid uit en geeft daartoe de nodige instructies aan de nationale centrale banken. ${ }^{24}$ De Raad van Bestuur bestaat uit de leden van de directie $^{25}$ en de presidenten van de nationale centrale banken van de eurolidstaten. ${ }^{26}$ De presidenten van de nationale centrale banken van niet-eurolidstaten zijn niet betrokken in de Europese besluitvorming inzake het monetair beleid. De nationale centrale banken van niet-eurolidstaten zijn ook niet betrokken in de operationele implementatie van het Europees monetair beleid. ${ }^{27}$ De Algemene Raad bestaat uit de president en de vicepresident van de ECB en de presidenten van de nationale centrale banken van alle lidstaten. ${ }^{28}$ De Algemene Raad is een tijdelijk orgaan, dat zal worden ontbonden zodra alle lidstaten de euro hebben ingevoerd. Tot die tijd houdt de Algemene Raad zich onder meer bezig met de taken die zijn overgenomen van het Europees Monetair Instituut (de voorganger van de ECB) in het kader van de verwezenlijking van de EMU. ${ }^{29}$

In verband met haar toezichtsfunctie heeft de ECB sinds 4 november 2014 een Raad van Toezicht. ${ }^{30}$ De Raad van Toezicht bereidt voor de Raad van Bestuur ontwerpbesluiten voor met betrekking tot de aan de ECB opgedragen toezichtstaken. ${ }^{31}$ De Raad van Toezicht bestaat uit een voorzitter, een vicevoorzitter (gekozen uit de leden van de directie van de ECB), vier vertegenwoordigers van de $\mathrm{ECB}^{32}$ en vertegenwoordigers van de nationale bankentoezichthouders uit elke eurolidstaat. ${ }^{33}$ (CRR), Richtlijn 2014/59/EU (BRRD) en Richtlijn 2014/49/EU (DGS). Art. 9.3 en 45.1 van het Protocol.

24 Art. 12 van het Protocol.

25 De directie bestaat uit de president, de vicepresident en vier andere leden (art. 11 van het Protocol).

26 Art. 10.1 en 43.4 van het Protocol. Sinds 1 januari 2015 zijn er negentien eurolidstaten. Ieder lid van de directie heeft een stem. Het aantal presidenten van nationale centrale banken met stemrecht bedraagt sinds 1 januari 2015 vijftien. Er is sprake van roulatie van de stemrechten tussen de presidenten.

27 Art. 43 van het Protocol; ECB, The monetary policy of the ECB, 2011, p. 13.

28 Art. 45.2 van het Protocol.

29 Art. 47 en 44 van het Protocol.

30 Art. 26 van de SSM-Verordening.

31 Art. 26 lid 8 van de SSM-Verordening.

32 Deze vertegenwoordigers mogen geen taken vervullen die rechtstreeks verband houden met de monetaire functie van de ECB (art. 26 lid 5 van de SSM-Verordening).

33 Ieder lid van de Raad van Toezicht heeft één stem. Bij staking van de stemmen is de stem van de voorzitter doorslaggevend. Art. 26 lid 6 van de SSM-Verordening. 


\subsection{Onafhankelijkheid en verantwoording}

Een belangrijk uitgangspunt bij de uitoefening van de monetairbeleidsfunctie en toezichtsfunctie is de onafhankelijkheid van de ECB. ${ }^{34}$ Het is de ECB (en overigens ook de nationale centrale banken van lidstaten) niet toegestaan om bij de uitoefening van haar bevoegdheden en het vervullen van haar taken en plichten instructies te vragen dan wel te aanvaarden van Europese instellingen, organen of instanties, van regeringen van lidstaten of van enig ander orgaan. Al deze partijen verplichten zich ertoe dit beginsel van onafhankelijkheid te eerbiedigen en niet te trachten de leden van de besluitvormende organen van de ECB (of de nationale centrale banken) bij de uitvoering van hun taken te beïnvloeden.

De onafhankelijkheid van de ECB neemt niet weg dat de ECB democratische verantwoording dient af te leggen. Voor wat betreft haar monetairbeleidsfunctie legt de ECB deze verantwoording af door het publiceren van maandberichten, weekstaten en jaarverslagen. ${ }^{35}$ De president van de ECB presenteert het jaarverslag aan het Europees Parlement. Daarnaast verschijnt de president vier keer per jaar voor de Commissie Economische en Monetaire Zaken van het Europees Parlement. ${ }^{36}$

In haar mededeling van 28 november 2012 stelde de Europese Commissie dat de democratische verantwoordingsplicht van de ECB voor haar toezichtsfunctie moest worden versterkt. ${ }^{37}$ Als gevolg hiervan is vastgelegd dat de ECB met betrekking tot de uitvoering van haar toezichtsfunctie verantwoordingsplichtig is tegenover het Europees Parlement en de Raad (als democratisch gelegitimeerde instellingen die de burgers van de Europese Unie en de lidstaten vertegenwoordigen). ${ }^{38}$ Deze verantwoordingsplicht strekt verder dan de verantwoordingsplicht voor de monetairbeleidsfunctie. De ECB moet bijvoorbeeld haar volledige medewerking verlenen aan onderzoeken door het Europees Parlement. ${ }^{39}$

\subsection{Kapitaal}

Het kapitaal van de ECB wordt bijeengebracht door de nationale centrale banken van alle lidstaten. ${ }^{40} \mathrm{Zij}$ zijn de enige aandeelhouders van de ECB. De inschrijving

34 Voor de monetairbeleidsfunctie is deze onafhankelijkheid vastgelegd in art. 130 VWEU en art. 7 van het Protocol. Voor de toezichtsfunctie is deze onafhankelijkheid vastgelegd in art. 19 van de SSM-Verordening.

35 Art. 15 van het Protocol.

36 ECB, The accountability of the ECB, ECB Monthly Bulletin, november 2002, p. 54.

37 Preambule 85 van de SSM-Verordening.

38 Art. 20 lid 1 van de SSM-Verordening.

39 Art. 20 lid 9 van de SSM-Verordening. Overigens beantwoordt de ECB in de praktijk ook vragen van Europarlementariërs over haar monetair beleid, alhoewel hier geen wettelijke basis voor is (zie noot 36).

40 Art. 28.2 en 43.5 van het Protocol. 
op het kapitaal geschiedt volgens een kapitaalverdeelsleutel. ${ }^{41}$ De nationale centrale banken buiten het eurogebied hoeven slechts een deel $(3,75 \%)$ van hun aandeel in het geplaatste kapitaal van de ECB te storten als bijdrage aan de bedrijfskosten van de ECB. ${ }^{42} \mathrm{Zij}$ hebben geen recht op een aandeel in de eventueel te verdelen winst van de ECB en hoeven ook niet bij te dragen in geval van eventuele verliezen van de ECB. ${ }^{43}$

\subsection{Belangenconflicten}

Gelet op het feit dat de ECB thans zowel een monetairbeleidsfunctie als een toezichtsfunctie heeft, kunnen er belangenconflicten optreden. Het QE-programma heeft bijvoorbeeld, onder meer, als doel dat de activakant van de balansen van banken wijzigt. De ECB en de nationale centrale banken kopen staatsobligaties van banken, met als doel dat de banken (centralebank)geld verkrijgen waarmee zij kredieten kunnen verstrekken. De bank houdt in dat geval als activa op haar balans niet langer staatsobligaties, maar vorderingen op kredietnemers (bijvoorbeeld consumenten). Dit kan gevolgen hebben voor het vereiste risicokapitaal dat een bank moet aanhouden. ${ }^{44}$ Of een bank voldoende risicokapitaal aanhoudt en derhalve voldoet aan de prudentiële eisen, wordt gecontroleerd door de ECB (indien het gaat om een significante bank). Vanuit monetairbeleidsperspectief kan het kortom wenselijk zijn dat een bank krediet verstrekt, terwijl dit vanuit toezichtsperspectief minder wenselijk kan zijn als een bank in dat geval niet meer aan de prudentiële eisen kan voldoen. Gelet op deze verschillende belangen moet de ECB de monetairbeleidsfunctie en toezichtsfunctie volledig gescheiden uitvoeren. ${ }^{45}$ In verband daarmee heeft er een organisatorische scheiding van het personeel plaatsgevonden. ${ }^{46}$ Onderdeel daarvan is dat de verantwoordelijkheid voor de toezichtstaken bij de speciaal daarvoor opgerichte Raad van Toezicht ligt (zoals besproken in par. 2.2), een bemiddelingspanel is opgericht ${ }^{47}$ en de ECB regels

41 Art. 28 en 29 van het Protocol. Aan elke nationale centrale bank wordt een weging in de sleutel toegekend die gelijk is aan de som van (1) $50 \%$ van het aandeel van de eurolidstaat in kwestie in de bevolking van de EU tijdens het voorlaatste jaar voorafgaand aan de oprichting van het ESCB, en (2) $50 \%$ van het aandeel van de eurolidstaat in kwestie in het bruto binnenlands product van de EU tegen marktprijzen, als vastgesteld tijdens de vijf jaar voorafgaande aan het voorlaatste jaar voor de oprichting van het ESCB. De wegingen worden om de vijf jaar aangepast.

42 Besluit van de Europese Centrale Bank van 30 augustus 2013 betreffende de volstorting van het kapitaal van de Europese Centrale Bank door de nationale centrale banken van buiten het eurogebied (ECB/2013/31).

43 Art. 33 van het Protocol. ECB, Jaarrekening 2014, p. 51.

44 Hoe hoger het risico is dat de kredietnemer het krediet niet terugbetaalt, hoe meer risicokapitaal een bank moet aanhouden. Zie art. 112 e.v. van de Verordening (EU) 575/2013 (CRR).

45 Art. 25 en overweging 65 van de SSM-Verordening.

46 Voor meer informatie zie het Jaarverslag van de ECB over haar toezichtswerkzaamheden 2014 van maart 2015.

47 Verordening (EU) 673/2014 van de Europese Centrale Bank van 2 juni 2014 betreffende de oprichting van een bemiddelingspanel en zijn reglement van orde (ECB/2014/26). Het bemiddelingspanel lost meningsverschillen van de bevoegde autoriteiten van de betrokken lidstaten op met betrekking tot mogelijke bezwaren van de Raad van Bestuur tegen een ontwerpbesluit van de Raad van Toezicht. 
heeft vastgesteld voor de uitwisseling van vertrouwelijke informatie tussen de monetairbeleidsfunctie en toezichtsfunctie. ${ }^{48}$

\section{De instrumenten van het monetair beleid}

In het navolgende zal ik nader toelichten welke instrumenten van het monetair beleid de ECB tot haar beschikking heeft. Ik zal ook kort ingaan op de Griekse situatie en de rol die de ECB hierin speelt.

\subsection{Conventionele instrumenten van het monetair beleid}

De (conventionele) instrumenten van het monetair beleid staan omschreven in deel 2 van het Richtsnoer betreffende de tenuitvoerlegging van het monetair beleidskader van het Eurosysteem (hierna: het Richtsnoer). ${ }^{49}$ Het Eurosysteem hanteert de volgende monetairbeleidsinstrumenten: de uitvoering van openmarkttransacties, het aanbieden van permanente faciliteiten en het verplichten van banken tot het aanhouden van minimumreserves op rekeningen binnen het Eurosysteem. ${ }^{50} \mathrm{Ik}$ zal deze instrumenten hieronder nader toelichten.

\section{- Openmarkttransacties}

Openmarkttransacties beogen de goede werking van de geldmarkt te waarborgen en de banken soepel en goed georganiseerd te helpen bij het voorzien in hun liquiditeitsbehoeften. Voor het uitvoeren van openmarkttransacties beschikt het Eurosysteem over vijf instrumenten: transacties met wederinkoop, ${ }^{51}$ onvoorwaardelijke aan- of verkoop van waardepapier, ${ }^{52}$ de uitgifte van ECB-schuldbewijzen,

48 Besluit van de Europese Centrale Bank van 17 september 2014 houdende de tenuitvoerlegging van scheiding tussen de monetaire beleidsfunctie en de toezichtfunctie van de Europese Centrale Bank (ECB/2014/39).

49 Richtsnoer (EU) 2015/510 van de Europese Centrale Bank betreffende de tenuitvoerlegging van het monetairbeleidskader van het Eurosysteem (ECB/2014/60) (herschikking), zoals gewijzigd door richtsnoer (EU) 2015/732 van de Europese Centrale Bank van 16 april 2015 houdende wijziging van Richtsnoer (EU) 2015/510 betreffende de tenuitvoerlegging van het monetairbeleidskader van het Eurosysteem.

50 Art. 3 van het Richtsnoer.

51 Bij transacties met wederinkoop koopt of verkoopt een nationale centrale bank beleenbare activa krachtens een repo-overeenkomst of verricht een nationale centrale bank krediettransacties in de vorm van leningen op onderpand (art. 2 sub 80 van het Richtsnoer). Bij een repo-overeenkomst is er sprake van een verkoop van beleenbare activa tegen contante euro's, terwijl tegelijkertijd wordt overeengekomen om op een bepaalde datum tegen contante euro's equivalente activa terug te verkopen (art. 176 van het Richtsnoer).

52 Bij onvoorwaardelijke aan- of verkopen van waardepapier gaat de volledige eigendom over van de verkoper naar de koper zonder een daarmee verbonden heroverdracht van eigendom (art. 14 lid 1 van het Richtsnoer). 
deviezenswaps ${ }^{53}$ en het aantrekken van termijndeposito's. ${ }^{54}$ Gelet op de doelstelling, frequentie en procedures kunnen de openmarkttransacties in vier categorieën worden ingedeeld: ${ }^{55}$

1 Basisherfinancieringstransacties: dit zijn reguliere liquiditeitsverruimende transacties die wekelijks worden uitgevoerd en doorgaans een looptijd van een week kennen. Basisherfinancieringstransacties worden exclusief uitgevoerd door middel van transacties met wederinkoop.

2 Langerlopende herfinancieringstransacties: dit zijn liquiditeitsverruimende transacties die maandelijks worden uitgevoerd en doorgaans een looptijd kennen van drie maanden. Langerlopende herfinancieringstransacties worden exclusief uitgevoerd door middel van transacties met wederinkoop.

3 Finetuningstransacties: dit kunnen zowel liquiditeitsverruimende als liquiditeitsverkrappende transacties zijn die worden uitgevoerd op ad-hocbasis met als specifiek doel het omgaan met fluctuaties in de liquiditeitsverhoudingen op de markt. ${ }^{56}$ Finetuningstransacties worden meestal uitgevoerd als transacties met wederinkoop, maar ook wel in de vorm van deviezenswaps of het aantrekken van termijndeposito's.

4 Structurele transacties: dit kunnen zowel liquiditeitsverruimende als liquiditeitsverkrappende transacties zijn die onder meer worden uitgevoerd wanneer de ECB de structurele positie van het Eurosysteem ten opzichte van de financiële sector wil beïnvloeden. ${ }^{57}$ Structurele transacties kunnen worden uitgevoerd door middel van uitgifte van ECB-schuldbewijzen, transacties met wederinkoop en onvoorwaardelijke aan- of verkoop van waardepapier.

Openmarkttransacties worden normaal gesproken uitgevoerd door de nationale centrale banken met in aanmerking komende wederpartijen (waaronder banken) ${ }^{58}$ door middel van tenderprocedures ${ }^{59}$ of bilaterale transacties (dit laatste is alleen mogelijk voor finetuningstransacties en structurele transacties). ${ }^{60}$ Onder uitzonderlijke omstandigheden zal de ECB zelf openmarkttransacties uitvoeren.

53 Bij een deviezenswap koopt of verkoopt het Eurosysteem contante euro's tegen een vreemde valuta onder gelijktijdige verkoop of aankoop op termijn per een overeengekomen datum (art. 2 sub 40 van het Richtsnoer).

54 Het aantrekken van termijndeposito's houdt in dat het Eurosysteem wederpartijen in de gelegenheid stelt termijndeposito's te plaatsen op rekeningen bij hun eigen nationale centrale banken teneinde liquiditeiten aan de markt te onttrekken (art. 2 sub 9 van het Richtsnoer).

55 Zie art. 4 tabel 1 van het Richtsnoer.

56 Art. 8 lid 1 van het Richtsnoer.

57 Art. 9 lid 1 van het Richtsnoer.

58 Zie deel 3 van het Richtsnoer.

59 Een tenderprocedure is een procedure waarbij het Eurosysteem liquiditeiten aan de markt verstrekt of onttrekt, waarbij de nationale centrale bank transacties aangaat door het accepteren van inschrijvingen die door wederpartijen zijn ingediend na een openbare aankondiging (art. 2 sub 92 van het Richtsnoer).

60 Voor de voorwaarden waaronder bijvoorbeeld DNB monetaire beleidstransacties aangaat, verwijs ik naar de Voorwaarden Monetaire Beleidstransacties van DNB van mei 2015. 


\section{- Permanente faciliteiten}

Permanente faciliteiten worden verschaft door de nationale centrale banken aan banken $^{61}$ en bestaan uit de marginale beleningsfaciliteit en de depositofaciliteit. De marginale beleningsfaciliteit is een faciliteit ter verkrijging van zeer kortlopende liquiditeiten van het Eurosysteem door middel van een transactie met wederinkoop tegen een vooraf vastgestelde rente en onder het vereiste dat voldoende onderpand wordt verstrekt door de bank. ${ }^{62}$ De marginale beleningsfaciliteit kan worden gebruikt op specifiek verzoek of automatisch indien de betreffende bank een negatief saldo op haar vereveningsrekening bij de nationale centrale bank heeft. De depositofaciliteit is een faciliteit waarbij een bank onmiddellijk opvraagbare deposito's kan plaatsen bij het Eurosysteem via de eigen nationale centrale bank. Het op de depositofaciliteit toegepaste rentetarief kan positief, maar ook negatief zijn. Per 10 september 2014 is de depositorente $-0,20 \% .{ }^{63}$ Banken moeten kortom rente betalen aan de ECB als zij gebruik willen maken van de depositofaciliteit. Hiermee stuurt de ECB het gebruik van de depositofaciliteit, althans dat is het doel. ${ }^{64}$

\section{- Reserveverplichtingen}

Ingevolge art. 19 van het Protocol eist de ECB dat banken uit het eurogebied op rekeningen bij de nationale centrale banken minimumreserves aanhouden. Deze minimumreserves dienen hoofdzakelijk om de geldmarktrente te stabiliseren en een structureel liquiditeitstekort te bewerkstelligen (of te vergroten). ${ }^{65}$

\subsection{Onconventionele instrumenten van monetair beleid}

In aanvulling op de monetairbeleidsinstrumenten, zoals hiervoor uiteengezet, hanteert de ECB momenteel, als gevolg van de crises waardoor de Europese Unie wordt geteisterd, een aantal niet-gebruikelijke monetairbeleidsinstrumenten. Dit zijn programma's voor de aankoop van allerlei soorten activa met als (uiteindelijk) doel het bewerkstelligen van prijsstabiliteit in de eurozone. ${ }^{66}$ Momenteel is

61 Dit betreft banken die voldoen aan art. 55, met inachtneming van art. 57, van het Richtsnoer.

62 Art. 18 van het Richtsnoer.

63 ECB, Key ECB interest rates, <www.ecb.europa.eu>, geraadpleegd op 22 juli 2015.

64 Naast de depositorente stelt de ECB ook de marginale beleningsrente en de rente voor de basisherfinancieringstransacties vast. Hiermee kan zij vraag en aanbod, en daarmee de inflatie, op een indirecte wijze beïnvloeden.

65 Zie voor meer informatie Verordening (EG) 2531/98 van de Raad van 23 november 1998 met betrekking tot de toepassing van reserveverplichtingen door de Europese Centrale Bank, zoals gewijzigd, Verordening (EG) 1745/2003 van de Europese Centrale Bank van 12 september 2003 inzake de toepassing van reserveverplichtingen (ECB/2003/9), zoals gewijzigd, en bijlage I van het Richtsnoer.

66 De bevoegdheid tot het opstarten van deze programma's ontleent de ECB aan art. 18.1 van het Protocol. 
een aantal programma's actief, waaronder CBPP3, ${ }^{67} \mathrm{ABSPP}^{68}$ en $\mathrm{PSPP}^{69}$ (het PSPP-programma wordt ook wel aangeduid als het QE-programma).

Het OMT-programma, zoals eerder aangehaald in paragraaf 1 van dit artikel, is ook een voorbeeld van een programma voor aankoop van activa (namelijk staatsobligaties).$^{70}$ De president van de ECB, Mario Draghi, liep vooruit op het OMTprogramma in een speech op de Global Investment Conference in Londen op 26 juli 2012 met de - inmiddels legendarische - woorden: 'Within our mandate, the $\mathrm{ECB}$ is ready to do whatever it takes to preserve the euro. And believe me, it will be enough.' Hoewel het OMT-programma tot op heden nog niet actief is, ${ }^{71}$ bleken alleen deze woorden al effectief te zijn.

Het OMT-programma is vergelijkbaar met het QE-programma, met dien verstande dat het OMT-programma is gericht op staatsobligaties uitgegeven door centrale overheden van specifieke eurolanden (die een beroep hebben gedaan op steun van het EFSF/ESM ${ }^{72}$ ), terwijl het QE-programma, in beginsel, betrekking heeft op staatsobligaties uitgegeven door centrale overheden van alle eurolanden. Een ander verschil tussen het QE-programma en het OMT-programma is dat de ECB aankopen van staatsobligaties onder het OMT-programma 'steriliseert' (neutraliseert) via tegengestelde transacties. Hierdoor is er onder het OMT-programma geen sprake van toename van de geldhoeveelheid in het eurogebied, hetgeen wel het geval is bij het QE-programma. Hieronder ga ik nader in op het QEprogramma.

67 Besluit van de Europese Centrale Bank van 15 oktober 2014 houdende de tenuitvoerlegging van het derde programma voor de aankoop van gedekte obligaties (ECB/2014/40). CBPP3 betreft kort gezegd het derde programma voor de aankoop op de primaire en secundaire markten door de ECB en de nationale centrale banken van de eurolidstaten van gedekte obligaties die zijn uitgegeven door banken uit de eurolidstaten.

68 Besluit (EU) 2015/5 van de Europese Centrale Bank van 19 november 2014 houdende de tenuitvoerlegging van het programma voor de aankoop van effecten op onderpand van activa (ECB/ 2014/45). ABSPP betreft kort gezegd een programma voor de aankoop op de primaire en secundaire markten door de ECB van effecten op onderpand van activa (asset-backed securities, ABS) die zijn uitgegeven door ABS-emittenten uit de eurolidstaten. De ECB heeft vier agenten (ING Investment Management, Amundi, Deutsche Asset \& Wealth Management International en State Street Global Advisors) aangewezen voor het keuren en aankopen van de ABS's (Persbericht ECB, ECB appoints executing asset managers for the ABS Purchase Programme, 30 oktober 2014).

69 Besluit (EU) 2015/774 van de Europese Centrale Bank van 4 maart 2015 inzake een overheidsprogramma voor aankoop van activa op secundaire markten (ECB/2015/10).

70 ECB, Technical features of Outright Monetary Transactions, 6 februari 2012.

71 ECB, De geconsolideerde weekstaat van het Eurosysteem per 21 augustus 2015, 25 augustus 2015.

72 De EFSF (Europese Faciliteit voor Financiële Stabiliteit) is in juni 2010 opgezet als tijdelijk noodfonds. De EFSF heeft steun verleend aan Ierland, Portugal en Griekenland. Momenteel verloopt de steunverlening via het permanente noodfonds, het Europees stabiliteitsmechanisme (ESM). Het ESM heeft steun verleend aan Spanje en Cyprus. 


\section{- Het QE-programma}

Het QE-programma is het meest recente aankoopprogramma van de ECB. Binnen dit programma kopen de ECB en de nationale centrale banken van de eurolidstaten vanaf maart 2015 van in aanmerking komende wederpartijen ${ }^{73}$ op de secundaire markten onvoorwaardelijk beleenbare verhandelbare schuldbewijzen aan. Het gaat om schuldbewijzen uitgegeven door centrale overheden van eurolidstaten $^{74}$ (staatsobligaties), erkende in het eurogebied gevestigde agentschappen, in het eurogebied gevestigde internationale organisaties en in het eurogebied gevestigde multilaterale ontwikkelingsbanken. Onder uitzonderlijke omstandigheden kunnen ook schuldbewijzen uitgegeven door andere uitgevers onder het QE-programma vallen. Om de marktprijsvorming van de schuldbewijzen mogelijk te maken moet er een bepaalde periode zitten tussen de uitgifte en de opkoop van het schuldbewijs (de zogenoemde black-outperiode).

Van de totale waarde van het QE-programma is $12 \%$ beschikbaar voor de aankoop van schuldbewijzen uitgegeven door internationale organisaties en multilaterale ontwikkelingsbanken en $88 \%$ voor de aankoop van staatsobligaties en schuldbewijzen uitgegeven door agentschappen. De nationale centrale banken van de eurolidstaten kopen schuldbewijzen aan voor $92 \%$ van de totale waarde. $8 \%$ wordt rechtstreeks door de ECB gekocht. De spreiding van de aankopen over de nationale centrale banken vindt plaats overeenkomstig de kapitaalverdeelsleutel (zoals eerder in dit artikel besproken). Elke nationale centrale bank koopt met name schuldbewijzen van uitgevers uit haar eigen jurisdictie aan. De ECB koopt schuldbewijzen van uitgevers uit alle jurisdicties.

Beoogd wordt tot eind september 2016 aankopen te doen onder het QE-programma, en in elk geval tot de Raad van Bestuur van de ECB vaststelt dat de inflatieontwikkeling stabiel is. De gecombineerde maximumomvang van de PSPP-, CBPP3- en ABSPP-programma's bedraagt $€ 60$ miljard per maand. ${ }^{75}$

Als gevolg van het QE-programma zullen de ECB en de nationale centrale banken nieuwe risico's op hun balans nemen (namelijk de gekochte schuldbewijzen). In 2013 heeft de Nederlandse Staat een garantie aan De Nederlandsche Bank (DNB) verstrekt voor het balansrisico van DNB als gevolg van een ander programma voor de aankoop van activa, het Securities Markets Programme (SMP). ${ }^{76}$ Eventuele verliezen uit hoofde van het QE-programma worden niet gedekt door deze garantie. DNB heeft vooralsnog geen aanleiding gezien om additionele garanties te vragen of haar financiële buffers te verhogen. De totale brutoblootstelling van Nederland binnen de PSPP-, CBPP3- en ABSPP-programma's bedraagt $€ 65$ miljard. ${ }^{77}$

73 In aanmerking komende wederpartijen zijn onder meer banken. Zie art. 7 van het Besluit (EU) 2015/774.

74 Met dien verstande dat er wel een bepaalde kredietkwaliteitbeoordeling moet zijn (art. 3 lid 2 van het Besluit (EU) 2015/774).

75 Overweging 7 van het Besluit (EU) 2015/774.

76 Het SMP is beëindigd op 6 september 2012 en vervangen door het OMT-programma.

77 Kamerstukken II 2014/15, 34200 IX, 2. 


\subsection{De Griekse situatie}

De ECB komt de laatste tijd vaak in het nieuws in verband met de financiële situatie van Griekenland. De ECB, of beter gezegd de centrale bank van Griekenland

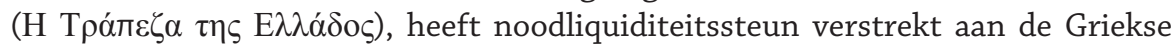
banken. ${ }^{78}$ Noodliquiditeitssteun is geen instrument van monetair beleid, maar een ander instrument om, onder exceptionele omstandigheden, centralebankkrediet te verschaffen aan solvente banken in het eurogebied die kampen met tijdelijke financiële problemen. ${ }^{79}$ Het verstrekken van noodliquiditeitssteun mag niet de doelstellingen en taken van het Eurosysteem doorkruisen. De Raad van Bestuur van de ECB dient dit te beoordelen. ${ }^{80}$ Banken die centralebankkrediet verkrijgen via noodliquiditeitssteun moeten onderpand verschaffen en betalen een hogere rente dan banken die centralebankkrediet verkrijgen via monetairbeleidsinstrumenten. ${ }^{81}$ De kosten en het risico van de noodliquiditeitssteun rusten bij de nationale centrale bank van de eurolidstaat waarin de banken die de steun ontvangen, zijn gevestigd. ${ }^{82}$

\section{Het arrest van het Hof van Justitie en het mandaat van de ECB}

$\mathrm{Na}$ voorgaande uiteenzetting van de functies en inrichting van de ECB en haar instrumenten van monetair beleid, zal ik nu ingaan op het arrest van het Hof van Justitie inzake de verenigbaarheid van het OMT-programma met het mandaat van de ECB, de lessen die hieruit kunnen worden getrokken voor het QE-programma en de mogelijke gevolgen die dit arrest heeft voor de onafhankelijkheid van de ECB.

De aanleiding voor het arrest van het Hof van Justitie over het OMT-programma op 16 juni $2015^{83}$ was een procedure die door een aantal partijen in Duitsland, waaronder de Duitse politieke partij Die Linke en de heer Gauweiler, aanhangig was gemaakt voor het Bundesverfassungsgericht tegen de Deutsche Bundestag en Bundesregierung. Zij stelden zich op het standpunt dat de Deutsche Bundestag en Bundesregierung ten onrechte hadden stilgezeten met betrekking tot het besluit van de ECB tot het OMT-programma. Volgens genoemde partijen is het OMTprogramma niet alleen een ultra vires-handeling, omdat het programma niet binnen het mandaat van de ECB valt, maar maakt het ook inbreuk op art. 123 VWEU 
(het verbod op monetaire financiering) en is het in strijd met de Duitse grondwet. Ik ga in dit artikel alleen in op het argument dat het programma niet binnen het mandaat van de ECB past. ${ }^{84}$

Het Bundesverfassungsgericht heeft in deze procedure, voor het eerst in zijn geschiedenis, besloten om prejudiciële vragen te stellen aan het Hof van Justitie. Het Bundesverfassungsgericht overweegt hierbij expliciet dat uit de rechtspraak van het Hof van Justitie volgt dat de onafhankelijkheid van de ECB niet in de weg staat aan een beoordeling van haar mandaat, aangezien deze onafhankelijkheid slechts de bevoegdheden van de ECB betreft en niet ziet op de omvang en reikwijdte van het mandaat. ${ }^{85}$ Het Bundesverfassungsgericht overweegt vervolgens dat er voldoende aanwijzingen zijn dat het OMT-programma geen monetaire, maar een economische beleidsmaatregel betreft, waarmee de ECB haar mandaat overschrijdt. $^{86}$

Advocaat-generaal bij het Hof van Justitie Cruz Villalon (hierna: de A-G) heeft op 14 januari 2015 zijn conclusie genomen in deze zaak. ${ }^{87}$ Volgens de A-G valt het OMT-programma onder het monetair beleid dat bij het EG-Verdrag aan de ECB is opgedragen, en vormt het geen economische beleidsmaatregel, mits de ECB zich gedurende de gehele uitvoering van het OMT-programma onthoudt van elke directe bemoeienis met de financiële hulpprogramma's waaraan het OMT-programma is gekoppeld (EFSF/ESM) ${ }^{88}$ Daarnaast concludeert de A-G dat het OMTprogramma niet het evenredigheidsbeginsel schendt, op voorwaarde dat strikt aan de vereisten van motivering en evenredigheid wordt voldaan in het geval het programma tot uitvoering moet worden gebracht. ${ }^{89}$

Het Hof van Justitie volgt de A-G op hoofdlijnen in zijn conclusie. Volgens het Hof van Justitie dient art. 130 VWEU (waarin het onafhankelijkheidsbeginsel is opgenomen) de ECB te vrijwaren van elke politieke druk, zodat zij de bij haar taken behorende doelstellingen doeltreffend kan nastreven door de onafhanke-

84 Het verbod op monetaire financiering houdt in dat het de ECB en de nationale centrale banken niet is toegestaan om rechtstreeks staatsobligaties van nationale overheden of lidstaten te kopen of kredietfaciliteiten te verlenen aan nationale overheden. Zowel de A-G als het Hof van Justitie heeft geconcludeerd c.q. geoordeeld dat het verbod op monetaire financiering de ECB alleen verbiedt om direct, op de primaire markt, staatsobligaties op te kopen. Het indirect kopen van staatsobligaties op de secundaire markt is wel toegestaan. Hier zijn echter wel voorwaarden aan verbonden om te voorkomen dat de ECB het verbod omzeilt. Deze voorwaarden houden onder meer in dat een marktprijs voor staatsobligaties kan worden gevormd voordat de ECB of de nationale centrale banken aankopen doen.

85 Noot 83, randnr. 8. Zie ook HvJ EG 10 juli 2003, C-11/00, ECLI:EU:C:2003:395 (Commissie/ ECB), randnr. 130-145.

86 Noot 87, randnr. 93. De ECB mag het algemene economische beleid van de Europese Unie ondersteunen (art. 3 van het Protocol), maar het OMT-programma zou verder gaan dan 'ondersteuning'.

87 Conclusie A-G Cruz Villalon, 14 januari 2015, C-62/14, ECLI:EU:C:2015:7 (Gauweiler). Zie voor een uitgebreide bespreking van de conclusie van de A-G S.P. Poppelaars, De dans tussen de ECB, het Bundesverfassungsgericht en het Hof van Justitie, NJB 2015/349, afl. 7, p. 420-428.

88 Noot 87, randnr. 158.

89 Noot 87, randnr. 202 
lijke uitoefening van de specifieke bevoegdheden waarover zij daartoe ingevolge het primair recht beschikt. De ECB moet uiteraard wel handelen binnen de grenzen van de bevoegdheden die haar door het primair recht worden verleend. De ECB mag dus geen programma vaststellen en uitvoeren dat het gebied te buiten gaat dat door het primair recht aan het monetair beleid is toegewezen. Om eerbiediging van dit beginsel te verzekeren zijn de handelingen van de ECB onderworpen aan het rechterlijk toezicht van het Hof van Justitie. ${ }^{90}$

Het Hof van Justitie merkt vervolgens op dat het VWEU nergens het monetair beleid nauwkeurig definieert, maar wel de doelstellingen en middelen (instrumenten) van het monetair beleid vastlegt. ${ }^{91}$ Teneinde vast te stellen of een maatregel onder het monetair beleid valt, moet hoofdzakelijk worden gekeken naar de doelstellingen van de maatregel. Daarnaast zijn de middelen die deze maatregel aanwendt om die doelstellingen te verwezenlijken relevant. ${ }^{92}$

Ten aanzien van de doelstellingen van het OMT-programma (een adequate transmissie van het monetair beleid en het verzekeren van de gemeenschappelijkheid van het monetair beleid) overweegt het Hof van Justitie dat deze in verband kunnen worden gebracht met het hoofddoel van de ECB (handhaven van prijsstabiliteit). ${ }^{93}$ Daarnaast wordt in het OMT-programma gebruik gemaakt van één van de in het primair recht vastgestelde instrumenten van monetair beleid, namelijk onvoorwaardelijke aan- en verkoop van waardepapier. ${ }^{94}$

Het Hof van Justitie gaat vervolgens in op de criteria die het Bundesverfassungsgericht opwerpt in zijn prejudiciële vragen en waaraan volgens het Bundesverfassungsgericht met name zou moeten worden getoetst of het OMT-programma verenigbaar is met het mandaat van de ECB. ${ }^{95}$ Deze criteria zijn voorwaardelijkheid, selectiviteit, parallellisme en omzeiling. Het Hof van Justitie overweegt ten aanzien van deze criteria het volgende:

1 Voorwaardelijkheid: de omstandigheid dat de uitvoering van het OMT-programma afhankelijk is van de naleving door de lidstaat van de programma's van de EFSF of het ESM doet niet ter zake.

2 Selectiviteit: er is geen verplichting voor de ECB om alleen door middel van algemene maatregelen die van toepassing zijn op alle eurolidstaten te opereren op de kapitaalmarkten.

3 Parallellisme: het doet niet ter zake dat het OMT-programma tot op zekere hoogte ook de verwezenlijking bevordert van doelstellingen van economisch beleid, en niet alleen monetair beleid.

4 Omzeiling: het kan worden uitgesloten dat het OMT-programma kan worden gebruikt om te ontsnappen aan de voorwaarden die het optreden van het ESM op de secundaire markt beperken, omdat het optreden van de ECB onaf-

90 Noot 83, randnr. 41.

91 Noot 83, randnr. 42. Ik verwijs naar par. 2 en 3 van dit artikel voor de doelstellingen en middelen van het monetair beleid.

92 Noot 83, randnr. 46.

93 Noot 83, randnr. 47-52.

94 Noot 83, randnr. 53-54.

95 Noot 83, randnr. 10. 
hankelijk moet worden uitgevoerd op basis van de eigen doelstellingen van het monetair beleid. ${ }^{96}$

Het Hof van Justitie acht de criteria van het Bundesverfassungsgericht kortom niet van belang voor beantwoording van de vraag of de ECB haar mandaat heeft overschreden, althans is van oordeel dat niet aan deze criteria is voldaan.

De evenredigheid van het OMT-programma vormt daarentegen wel een belangrijk toetsingselement voor het Hof van Justitie. Het Hof van Justitie overweegt dienaangaande dat de ECB bij het uitwerken en uitvoeren van een OMT-programma over een ruime beoordelingsbevoegdheid beschikt. Het toezicht op de inachtneming van bepaalde procedurele waarborgen is daarom van fundamenteel belang. ${ }^{97}$ Tot die waarborgen behoren de verplichtingen om alle relevante gegevens van de betrokken situatie zorgvuldig en onpartijdig te onderzoeken en om besluiten toereikend te motiveren. Gelet op de ruime beoordelingsbevoegdheid en het feit dat vragen van monetair beleid gewoonlijk omstreden zijn, kan echter niet meer worden verlangd dan dat de ECB gebruik maakt van haar economische deskundigheid en van de nodige technische middelen waarover zij beschikt om een analyse van de economische situatie van het eurogebied te maken. ${ }^{98}$ Het Hof van Justitie oordeelt vervolgens dat de ECB zich op het standpunt mocht stellen dat het OMT-programma geschikt is om bij te dragen aan de handhaving van prijsstabiliteit. $^{99}$

Om als evenredige maatregel te kwalificeren dient het OMT-programma echter niet alleen geschikt te zijn om bij te dragen aan de handhaving van prijsstabiliteit, het dient daarnaast niet kennelijk verder te gaan dan nodig is om die doelstelling te verwezenlijken. ${ }^{100}$ In dat kader overweegt het Hof van Justitie dat de aankoop van staatsobligaties op de secundaire markt binnen het OMT-programma alleen is toegestaan voor zover deze noodzakelijk is om de doelstellingen van het OMTprogramma te bereiken, aan de aankopen een einde zal komen zodra de doelstellingen zijn bereikt, en de potentiële omvang van het programma op verschillende wijzen wordt beperkt. ${ }^{101}$ Tot slot oordeelt het Hof dat de ECB de verschillende betrokken belangen onderling heeft afgewogen teneinde daadwerkelijk te voorkomen dat zich bij de uitvoering van het OMT-programma nadelen kunnen voordoen die kennelijk buiten verhouding staan tot de doelstellingen ervan (evenredigheidstoets stricto sensu). ${ }^{102}$

96 Noot 83, randnr. 55-65.

97 Noot 83, randnr. 68-69.

98 Noot 83, randnr. 69 en 75.

99 Noot 83, randnr. 80.

100 Noot 83, randnr. 81.

101 Deze beperkingen bestaan eruit dat de ECB slechts staatsobligaties mag opkopen van lidstaten die een beroep hebben gedaan op steun van de EFSF/het ESM, de staatsobligaties die worden gekocht een looptijd van minder dan drie jaar hebben, en de ECB zich de mogelijkheid voorbehoudt de gekochte obligaties te allen tijde opnieuw te verkopen. De totale geldelijke omvang van het OMT-programma is echter niet beperkt. Noot 82, randnr. 82-88.

102 Noot 83, randnr. 91 
Het Hof van Justitie komt kortom tot het oordeel dat het OMT-programma een evenredige maatregel is waarmee de ECB de grenzen van haar mandaat niet heeft overschreden. Opvallend is dat het Hof niet de voorwaarde stelt (zoals de A-G) dat de ECB zich onthoudt van iedere directe bemoeienis met de financiële hulpprogramma's waaraan het OMT-programma is gekoppeld (EFSF/ESM). Daarnaast lijkt de ECB minder streng te zijn dan de A-G ten aanzien van de evenredigheidstoets stricto sensu. De A-G stelt immers dat een definitieve beoordeling van de evenredigheid pas kan worden uitgevoerd nadat het OMT-programma tot uitvoering is gebracht. ${ }^{103}$ Het Hof van Justitie lijkt hier echter niet op te willen wachten en oordeelt al op voorhand dat het OMT-programma slaagt voor de evenredigheidstoets.

\subsection{De gevolgen van de uitspraak voor het QE-programma}

Uit de uitspraak van het Hof van Justitie kunnen drie belangrijke elementen worden gedestilleerd voor beantwoording van de vraag of de ECB binnen de grenzen van haar mandaat inzake het monetair beleid heeft gehandeld. Deze elementen zijn: doelstellingen, middelen en evenredigheid. Ik zal in het navolgende deze elementen bespreken voor het QE-programma.

\section{- Doelstellingen}

De doelstelling van het QE-programma is financieel intermediairs ertoe aan te zetten meer liquiditeiten aan de interbancaire markt en meer krediet aan de eurogebiedeconomie ter beschikking te stellen. ${ }^{104}$ Hiermee past de doelstelling van het QE-programma naar mijn mening binnen het hoofddoel van de ECB (handhaven van prijsstabiliteit), omdat hierdoor de consumptie en investeringen in het eurogebied worden ondersteund, hetgeen ertoe zal bijdragen dat de inflatie op het gewenste peil wordt gebracht.

\section{- $\quad$ Middelen}

Het QE-programma maakt, net als het OMT-programma, gebruik van onvoorwaardelijke aan- en verkoop van verhandelbaar papier. ${ }^{105}$ Dit is een instrument van monetair beleid dat de ECB ter beschikking staat op grond van art. 18.1 van het Protocol.

\section{- Evenredigheid}

De evenredigheidstoets valt uiteen in drie delen: geschiktheid, noodzakelijkheid en evenredigheid stricto sensu.

Het is lastig om een uitspraak over de geschiktheid van het QE-programma te doen. Uit het arrest van het Hof van Justitie volgt dat er sprake is van geschiktheid, als de ECB gebruik maakt van haar economische deskundigheid en van de nodige technische middelen waarover zij beschikt om met de grootste zorg en nauwkeurigheid een analyse van de economische situatie van het eurogebied te 
maken. Of een dergelijke analyse door de ECB is gemaakt, volgt niet met zoveel woorden uit haar besluit tot het QE-programma, al kan daar wel uit worden opgemaakt dat de ECB heeft vastgesteld dat de basisrentetarieven van de ECB het dal hebben bereikt en de andere aankoopprogramma's de neerwaartse risico's voor de prijsstabiliteit onvoldoende hebben kunnen adresseren. ${ }^{106}$ Hieruit zou (mogelijk) kunnen worden opgemaakt dat de ECB de benodigde analyse heeft gemaakt en het QE-programma derhalve een geschikte maatregel is.

Voor wat betreft de noodzakelijkheid is naar mijn mening van belang dat de omvang van het QE-programma vooraf kwantitatief is begrensd. De maandelijkse aankopen bedragen (in combinatie met de ABSPP- en CBPP3-programma's) maximaal $€ 60$ miljard per maand. Aan de aankopen zal een einde komen zodra de doelstellingen zijn bereikt. ${ }^{107}$ Daarnaast kan uit overweging 5 van het besluit tot het QE-programma worden opgemaakt dat het QE-programma een aantal waarborgen omvat om te verzekeren dat voorgenomen aankopen evenredig zullen zijn aan de doelstellingen en dat bij de uitwerking van het QE-programma, door middel van risicobeheer, genoegzaam rekening zal worden gehouden met de daarmee samenhangende financiële risico's. Welke waarborgen dit zijn, wordt echter niet verder uitgewerkt in het besluit. Hoe een beoordeling van de noodzakelijkheid van het QE-programma zal uitvallen, is derhalve op voorhand lastig te voorspellen, al verwacht ik dat de kwantitatieve beperking van de omvang van het QE-programma zal bijdragen aan een positieve beoordeling.

Gelet op de soepele toets die het Hof van Justitie lijkt te hanteren voor de evenredigheid stricto sensu, de belangenafweging, verwacht ik tot slot dat het niet snel zal oordelen dat een belangenafweging in het nadeel van de ECB zal uitslaan. Het besluit biedt echter op dit punt geen aanknopingspunten.

$\mathrm{Al}$ met al is het naar mijn mening waarschijnlijk dat het Hof van Justitie zal oordelen, indien deze vraag zal worden voorgelegd, dat de ECB met het QE-programma binnen de grenzen van haar mandaat is gebleven.

\section{Conclusie}

Het uitgangspunt is dat de ECB in onafhankelijkheid haar mandaat inzake het monetair beleid uitvoert. Door de uitspraak van het Hof van Justitie over het OMT-programma is in dit uitgangspunt geen wijziging gekomen. Wel is duidelijk dat het Hof van Justitie zich bevoegd acht te oordelen of de ECB binnen de grenzen van haar mandaat opereert.

Om te toetsen of de ECB met een bepaalde maatregel binnen de grenzen van haar mandaat opereert, bekijkt het Hof van Justitie ten eerste of de doelstellingen en de middelen om die doelstellingen te verwezenlijken passen binnen de hoofddoelstelling van de ECB (handhaven van prijsstabiliteit) en de wettelijke instrumenten van monetair beleid die haar ter beschikking staan. Daarnaast toetst het Hof van Justitie of de maatregel de evenredigheidstoets doorstaat. Via de evenredigheids- 
toets zou het Hof van Justitie de onafhankelijkheid van de ECB kunnen inperken, ware het niet dat het overweegt dat de ECB een ruime beoordelingsbevoegdheid heeft. Het Hof van Justitie toetst met name of de procedurele waarborgen in acht zijn genomen. De onafhankelijkheid van de ECB lijkt kortom door het Hof van Justitie te worden gewaarborgd. Mijn verwachting is dat dit in een eventuele procedure over het QE-programma niet anders zal zijn.

Ik sluit af met een opmerking over de toezichtsfunctie van de ECB. Ook voor de toezichtsfunctie geldt immers het beginsel van onafhankelijkheid. De vraag is of het Hof van Justitie, in het geval het zich moet uitspreken over toezichtsmaatregelen van de ECB, de onafhankelijkheid van de ECB in eenzelfde mate in acht zal nemen als het doet ten aanzien van de monetairbeleidsfunctie. Dit is niet alleen van belang voor de ECB, maar ook voor de partijen die (succesvol) een beroep tegen een toezichtsmaatregel van de ECB wensen in te stellen. De tijd zal het leren. ${ }^{108}$

108 Er is beroep ingesteld tegen de ECB bij het Hof van Justitie door Landeskreditbank Baden-Württemberg (zaak T-122/15). Dit beroep ziet op de kwalificatie van Landeskreditbank Baden-Württemberg door de ECB, in haar rol als toezichthouder, als significante bank. Volgens Landeskreditbank Baden-Württemberg is dit ten onrechte. Ten tijde van het schrijven van dit artikel is er nog geen uitspraak gedaan in deze zaak. 